\title{
BMJ Open Umbilical artery lactate levels and associated maternal and newborn characteristics at Mulago National Referral Hospital: a cross-sectional observational study
}

Victor Ogik (D , ${ }^{1}$ Mark Muyingo, ${ }^{1}$ Moses Musooko, ${ }^{2}$ Jolly Nankunda ${ }^{3}$

To cite: Ogik V, Muyingo M, Musooko M, et al. Umbilical artery lactate levels and associated maternal and newborn characteristics at Mulago National Referral Hospital: a cross-sectional observational study. BMJ Open 2021;11:e043827. doi:10.1136/ bmjopen-2020-043827

- Prepublication history for this paper is available online. To view these files, please visit the journal online (http://dx.doi. org/10.1136/bmjopen-2020043827).

Received 14 August 2020 Accepted 28 July 2021

Check for updates

(C) Author(s) (or their employer(s)) 2021. Re-use permitted under CC BY-NC. No commercial re-use. See rights and permissions. Published by BMJ.

${ }^{1}$ Department of Obstetrics and Gynecology, Makerere University College of Health Sciences, Kampala, Uganda

${ }^{2}$ Department of Obstetrics and Gynecology, Mulago National Referral Hospital, Kampala, Uganda

${ }^{3}$ Department of PediatricsNeonatology, Mulago National Referral Hospital, Kampala, Uganda

Correspondence to

Dr Victor Ogik:

victorkogik@gmail.com

\section{ABSTRACT}

Objective To determine the maternal and newborn characteristics associated with high umbilical artery lactate levels at Mulago National Referral Hospital. Design Cross-sectional observational study. Setting Department of Obstetrics and Gynecology at a national referral hospital located in the capital of Uganda, Kampala.

Participants We randomly selected 720 pregnant mothers at term who presented in labour and their newborn babies.

Primary outcome Umbilical artery lactate level. Results During the study, there were 579 vaginal deliveries (18 instrumental) and 141 caesarean sections which met the inclusion criteria. One hundred and eightyseven neonates (187) had high arterial lactate levels. The following factors were associated with an increased likelihood of high lactate concentration: male sex (adjusted OR $(\mathrm{aOR})=1.71 ; 95 \% \mathrm{Cl} 1.16$ to $2.54 ; \mathrm{p}<0.05)$, primigravidity ( $\mathrm{aOR}=2.78 ; 95 \% \mathrm{Cl} 1.89$ to $4.08 ; \mathrm{p}<0.001$ ), meconium-stained liquor $(\mathrm{aOR}=5.85 ; 95 \% \mathrm{Cl} 4.08$ to 8.47 $\mathrm{p}<0.001)$ and administration of oxytocin $(\mathrm{aOR}=1.97 ; 95 \%$ Cl 1.00 to 3.77 ; $p<0.05$ ).

Conclusion About a fifth of the babies born in Mulago National Referral Hospital during the study period had high umbilical artery lactate. The maternal-fetal factors significantly associated with high umbilical artery lactate levels included: baby's sex, mother's gravidity, meconiumstained amniotic fluid and oxytocin administration during labour.

\section{INTRODUCTION}

In 2018, the global burden of neonatal mortality was 18 deaths per 1000 live births with almost $80 \%$ of this burden in subSaharan Africa and Southern Asia (39\% and $38 \%$, respectively). ${ }^{1}$ In Uganda, birth asphyxia is among the leading causes of neonatal mortality and morbidity. It results from failure to, or breathing poorly, depriving body tissues of oxygen and leading to a hypoxic state, hypercapnia and metabolic acidosis. ${ }^{2}$
Strengths and limitations of this study

- Simple random sampling at recruitment reduced selection bias based on participant characteristics.

- The large participant sample size powered the study to derive meaningful/significant association between high lactate and associated characteristics.

- We used one arterial blood sample and therefore could not verify each sample as truly arterial and not venous blood.

During severe hypoxic states there is shift in the metabolic pathways to anaerobic glycolysis causing lactic acidaemia to rapidly develop. ${ }^{3}$ The quantification of lactic acid in neonatal cord arterial blood could therefore be a reflection of the current metabolic state of the neonate at birth.

From large observational studies it has been predetermined that newborn arterial cord blood levels greater than the 95th percentile are equivalent to $>6.1 \mathrm{mmol} / \mathrm{L}$ and greater than the 99th percentile equivalent to $>6.7 \mathrm{mmol} / \mathrm{L}^{4}{ }^{4}$ This study therefore considered a cut-off of $6.1 \mathrm{mmol} / \mathrm{L}$ as threshold for high cord blood lactate level.

There is no study known to us published on umbilical cord blood lactate levels in Mulago National Referral Hospital. However, a study on antenatal and intrapartum risk factors for birth asphyxia among obstetric referrals in this hospital found that augmentation of labour with oxytocin, premature rupture of membranes, meconium staining of liquor amnii, vacuumassisted delivery, caesarean section, low birth weight and malpresentations were significantly associated with birth asphyxia. ${ }^{6}$

This study was aimed at determining the maternal-fetal factors associated with high umbilical artery lactate levels at Mulago National Referral Hospital. 


\section{METHODS}

The study was a cross-sectional observational design. It was conducted at Mulago National Referral Hospital, Department of Obstetrics and Gynecology. The hospital is located centrally in Kampala, the capital of Uganda. This is a tertiary hospital providing comprehensive emergency obstetric and newborn care 24 hours/day. It is also a training hospital for Makerere University College of Health Sciences. There are about 39080 deliveries at this hospital annually.

The hospital has a level II special care unit for admission of sick newborns and premature babies with a capacity of 60 beds.

The target population was pregnant women who presented to deliver at the hospital labour suite between January and March 2019. The inclusion criteria were: pregnant women admitted in labour, with term gestation determined by a first trimester ultrasound scan or calculation from first day of last normal menstrual period, and a singleton gestation. Pregnant women who were suffering from complications such as eclampsia, antepartum haemorrhage and documented fever $\geq 38^{\circ} \mathrm{C}$ were excluded. Newborns who were delivered and subsequently diagnosed with congenital anomalies were excluded as well. During the study period there were 2968 deliveries and 720 mothers and their babies who met the inclusion criteria were recruited using systematic sampling. The sample size of 720 was arrived at using the formula for logistic regression models $(\mathrm{n}=10 \mathrm{~K} / \mathrm{P}){ }^{7}$ Reference was made to a study assessing umbilical cord $\mathrm{pH}$ and risk factors for acidaemia in neonates choosing the proportion of acidotic babies born through meconium-stained amniotic fluid. $^{8}$

Informed consent was obtained from the sampled mothers. Unique identification numbers were assigned to mothers who agreed to participate in the study as well as their neonates. The participants' baseline characteristics such as age, gravidity, gestational age and blood pressure were collected using a data form. Following vaginal or caesarean delivery, a $20 \mathrm{~cm}$ segment of umbilical cord was doubly clamped and one sample of $2 \mathrm{~mL}$ arterial blood drawn from between the clamps within 5 min of delivery. We deviated from the norm of paired blood samples to verify a sample as truly arterial and this was due to limited lactate test strips. ${ }^{9}$ The first study assistant immediately used $20-30 \mu \mathrm{L}$ of sampled blood and measured its lactate concentration using a point-of-care lactate metre (Accutrend Plus system; Roche Diagnostics, Rotkreuz, Switzerland). The precision range of the metre is $0.8-22 \mathrm{mmol} / \mathrm{L}$ at $15^{\circ} \mathrm{C}-35^{\circ} \mathrm{C}$ and the coefficient of variation is $1.8 \%-3 \%$. The study assistants did not interfere with the conduction of delivery and/or active management of the third stage of labour.

The newborn characteristics such as mode of delivery, sex, birth weight and exposure to meconium-stained amniotic fluid were also documented. We documented the Apgar score at 1 and $5 \mathrm{~min}$, if the neonate was resuscitated after birth, admitted to the nursery, and if they died.
It was also documented if the mother received any medication during the intrapartum period such as oxytocin, antibiotics, anticonvulsants (magnesium sulfate) and prostaglandins for labour induction.

Data were entered into EpiData V.4.4 (The EpiData Association, Odense, Denmark) and then exported to R V.3.5 (R Foundation for Statistical Computing, Vienna, Austria). All continuous variables were summarised as means, medians and ranges, while the categorical variables were summarised as percentages and proportions. Bivariate analysis was done by fitting a model for all the independent variables with the outcome high lactate and their CIs at $95 \%$ CI; all the variables that gave a $p$ value $\leq 0.2$ were considered for multivariate analysis. The logistic model was run for all the variables that met the criteria for the multivariate analysis and the variables which were found to be significantly $(\mathrm{p}<0.05)$ associated with high lactate were used to form two-way product terms. These product terms were used in the assessment of interaction by dropping the interaction terms one at a time starting with the least significant while the remaining ones were checked if they attained significance.

\section{Patient and public involvement}

Patients were not involved in the study design process. They were first involved in the study at recruitment when the study was explained to them and they gave their consent to participate. We only shared with the patients the lactate value of their baby's umbilical cord blood. The findings of the study will be packaged into key messages and disseminated to the patients during health education sessions as they wait to be attended to at prenatal clinics.

\section{RESULTS}

Over the study period, samples of unpaired umbilical artery cord blood were obtained from 720 neonates. The mean lactate value was $5.49 \pm \mathrm{SD} 2.44 \mathrm{mmol} / \mathrm{L}$. The IQR was $4.0-6.2 \mathrm{mmol} / \mathrm{L}$. Of the total, $187(25.97 \%)$ neonates had a high lactate value greater than $6.1 \mathrm{mmol} / \mathrm{L}$. The outcomes for neonates with high lactate differed significantly from those with low lactate; $47(25.1 \%)$ were resuscitated after birth versus $7(1.3 \%)$ with low lactate, $\chi^{2}(\mathrm{df}=1)=113.22, \mathrm{p}<0.001$. Secondly, $60(32.1 \%)$ with high lactate were admitted to the nursery versus $22(4.1 \%)$ with low lactate, $\chi^{2}(\mathrm{df}=1)=107.22, \mathrm{p}<0.001$. Thirdly, $34(19.8 \%)$ with high lactate were diagnosed with asphyxia (Apgar score less than 7 at $5 \mathrm{~min}$ ) versus 4 $(0.75 \%)$ with low lactate, $\chi^{2}(\mathrm{df}=1)=93.41, \mathrm{p}<0.001$. Lastly, $16(8.6 \%)$ with high lactate died versus $3(0.6 \%)$ with low lactate, $\chi^{2}(\mathrm{df}=1)=34.43, \mathrm{p}<0.001$. The 16 neonates with high lactate were diagnosed with hypoxic ischaemic encephalopathy (HIE) and this was a likely cause of death while neonatal sepsis was the cause of death in the three neonates with low lactate (one death occurring after discharge from our hospital). See table 1 summarising participant characteristics. 
Table 1 Baseline and clinical characteristics of the 720 study participants

\begin{tabular}{|c|c|c|}
\hline Characteristics & Frequency $(\mathrm{n})$ & $\%$ \\
\hline \multicolumn{3}{|l|}{ Mother's age (years) } \\
\hline $14-19$ & 112 & 15.56 \\
\hline 20-34 & 543 & 75.42 \\
\hline$\geq 35$ & 65 & 9.03 \\
\hline \multicolumn{3}{|l|}{ Gravidity } \\
\hline Primigravida & 259 & 35.97 \\
\hline Multigravida & 461 & 64.03 \\
\hline \multicolumn{3}{|l|}{ Gestational age } \\
\hline Early term $\left(37 \frac{0}{7}-38 \frac{6}{7}\right)$ & 266 & 36.9 \\
\hline $\operatorname{Term}\left(39 \frac{0}{7}-40 \frac{6}{7}\right)$ & 310 & 43.1 \\
\hline Late term $\left(41 \frac{0}{7}-41 \frac{6}{7}\right)$ & 76 & 10.6 \\
\hline Post-term $\left(\geq 42 \frac{0}{7}\right)$ & 68 & 9.4 \\
\hline \multicolumn{3}{|l|}{ Baby's sex } \\
\hline Male & 374 & 51.9 \\
\hline Female & 346 & 48.1 \\
\hline
\end{tabular}

Birth weight (g)

Average 3245.83

\begin{tabular}{lrr} 
Low (<2500) & 11 & 1.5 \\
\hline Normal (2500-3999) & 678 & 94.2 \\
\hline Macrosomia (>3999) & 31 & 4.3 \\
Maternal blood pressure & & \\
Normal (<140/90) & 659 & 91.5 \\
High (140/90-159/109) & 52 & 7.2 \\
\hline Severe (>159/109) & 9 & 1.3 \\
Medication during labour & & \\
None & 584 & 80.8 \\
Oxytocin & 54 & 7.5 \\
Antibiotics & 52 & 7.2 \\
Anticonvulsants & 7 & 0.9 \\
Antihypertensive & 19 & 2.6 \\
Prostaglandin & 4 & 0.6
\end{tabular}

Mode of delivery

$\begin{array}{lrr}\text { Spontaneous vertex delivery } & 561 & 77.9 \\ \text { Assisted vaginal delivery } & 18 & 2.5 \\ \text { Caesarean section } & 141 & 19.6\end{array}$

Unadjusted analysis found that mother's age, baby's sex, mother's gravidity, medication administered, mode of delivery and meconium staining had a $p$ value $<0.2$ and were considered for multivariate analysis. See table 2 showing unadjusted analysis of factors associated with high umbilical artery lactate levels.

Logistic regression analysis demonstrated that the following factors were associated with an increased likelihood of high lactate in a neonate: male sex (adjusted OR $(\mathrm{aOR})=1.71 ; 95 \%$ CI 1.16 to $2.54 ; \mathrm{p}<0.05)$, primigravidity $(\mathrm{aOR}=2.78 ; 95 \%$ CI 1.89 to 4.08 ; $\mathrm{p}<0.001)$, meconiumstained liquor $(\mathrm{aOR}=5.85 ; 95 \%$ CI 4.08 to $8.47 ; \mathrm{p}<0.001)$ and administration of oxytocics $(\mathrm{OR}=1.97 ; 95 \% \mathrm{CI} 1.00$ to $3.77 ; \mathrm{p}<0.05)$. See table 3 showing multivariate analysis of factors associated with high umbilical artery lactate levels.

\section{DISCUSSION}

This study was aimed at determining which maternal-fetal characteristics were significantly associated with newborn acidaemia. This was by a proxy measure of lactic acid concentration in an umbilical artery cord blood segment. From the study, four factors were found significantly associated as follows.

Male babies were $71 \%$ more likely to have a high lactate reading compared with female babies. The findings of this study are similar to a study in which male sex had significantly higher cord blood lactate levels $\left(R^{2}=0.34\right.$; $\mathrm{p}=0.034$ ) compared with female sex. ${ }^{10}$ In addition, a study exploring the effect of race on male predisposition to birth asphyxia concluded that male sex was $16 \%$ more likely to have severe birth asphyxia compared with female sex. ${ }^{11}$ These findings are in agreement with a United Nations report on sex differentials in childhood mortality which stated that in the 2000s, male to female newborn mortality in Uganda had a ratio of $1.26 .{ }^{12}$ There has been no conclusive explanation put forward as to why this difference in outcomes is observed. However, in a comprehensive review on the subject, it is concluded that differences in clinical outcomes between sexes may represent a complex interaction between immunological, hormonal and genetic factors and that further research is still warranted. ${ }^{13}$

The study found that primigravidas were more than two times likely to have high cord blood lactate as compared with multigravidas. Primigravidas are considered high-risk mothers because of the predisposition to adverse maternal and neonatal outcomes. Yuichi et al similarly found significantly lower cord arterial lactate levels $\left(R^{2}=0.34\right.$; $\mathrm{p}=0.001$ ) in babies born to mothers with higher gravidity and parity. ${ }^{10}$ In a second study, it was observed that 24 (61.5\%) of the babies with birth asphyxia were born to primigravidas and had a significantly higher mean cord arterial lactate $(6.423 \pm 2.335 \mathrm{mmol} / \mathrm{L})$ compared with 477 $(55 \%)$ babies without birth asphyxia $(3.6 \pm 1.832 \mathrm{mmol} / \mathrm{L})$ who were born to multigravidas $(\mathrm{p}=0.048) .{ }^{14}$

This study found that babies born through meconiumstained amniotic fluid were more than five times likely to have high cord arterial blood lactate levels compared with babies born through clear amniotic fluid. In a similar study assessing utility of a lactate-creatinine ratio for prediction of HIE, their concentrations were measured in urine passed by babies born through meconium-stained amniotic fluid within 6 hours of life. They found the mean lactate level $(21.6 \pm 34.83 \mathrm{mmol} / \mathrm{L})$ higher in babies exposed to meconium-stained amniotic fluid compared 
Table 2 Unadjusted analysis for the factors associated with the high umbilical artery lactate levels $(>6.1 \mathrm{mmol} / L)$ in neonates born in Mulago National Referral Hospital

\begin{tabular}{|c|c|c|c|c|c|}
\hline Characteristics & $\begin{array}{l}\text { Low lactate } \\
\mathrm{n}=533(\%)\end{array}$ & $\begin{array}{l}\text { High lactate } \\
\mathrm{n}=187(\%)\end{array}$ & OR & $95 \% \mathrm{Cl}$ & $P$ value \\
\hline \multicolumn{6}{|l|}{ Mother's age } \\
\hline $20-34$ & $410(75.5)$ & $133(24.5)$ & 1.00 & & \\
\hline$<20$ & $74(66.1)$ & 38 (33.9) & 1.58 & 1.02 to 2.44 & 0.04 \\
\hline$>35$ & $49(75.4)$ & $16(24.6)$ & 1.01 & 0.54 to 1.79 & 0.983 \\
\hline \multicolumn{6}{|l|}{ Baby's sex } \\
\hline Female & $275(79.5)$ & $71(20.5)$ & 1.00 & & \\
\hline Male & $258(69)$ & $166(31)$ & 1.74 & 1.24 to 2.46 & 0.001 \\
\hline \multicolumn{6}{|l|}{ Birth weight (kg) } \\
\hline Normal (2500-3999) & $502(74)$ & $176(26)$ & 1.00 & & \\
\hline LBW $(<2500)$ & $8(72.7)$ & $3(27.3)$ & 1.07 & 0.23 to 3.74 & 0.921 \\
\hline Macrosomia (>3999) & $23(74.2)$ & $8(25.8)$ & 0.99 & 0.41 to 2.17 & 0.985 \\
\hline \multicolumn{6}{|l|}{ Gestational age } \\
\hline Term (39-40) & $224(72.3)$ & $86(27.7)$ & 1.00 & & \\
\hline Early term (37-38) & $200(75.2)$ & $66(24.8)$ & 0.86 & 0.59 to 1.25 & 0.427 \\
\hline Late term (41-41) & $59(77.6)$ & $17(22.4)$ & 0.75 & 0.40 to 1.33 & 0.344 \\
\hline Post-term ( $\geq 42)$ & $50(73.5)$ & $18(26.5)$ & 0.94 & 0.51 to 1.67 & 0.832 \\
\hline \multicolumn{6}{|l|}{ Gravidity } \\
\hline Multigravida & $373(80.9)$ & $88(19.1)$ & 1.00 & & \\
\hline Primigravida & $160(61.8)$ & $99(38.2)$ & 2.66 & 1.89 to 3.71 & 0.000 \\
\hline \multicolumn{6}{|l|}{ Maternal blood pressure } \\
\hline Normal $(<140 / 90)$ & $475(74)$ & $167(26)$ & 1.00 & & \\
\hline High (140/90-159/109) & $39(75)$ & $13(25)$ & 0.95 & 0.48 to 1.77 & 0.873 \\
\hline Severe $(>159 / 109)$ & $5(55.6)$ & $4(44.4)$ & 2.26 & 0.56 to 8.70 & 0.224 \\
\hline \multicolumn{6}{|l|}{ Medication administered } \\
\hline None & $437(74.8)$ & $147(25.2)$ & 1.00 & & \\
\hline Antibiotics & $39(75)$ & $13(25)$ & 0.56 & 0.24 to 1.27 & 0.164 \\
\hline Anticonvulsants & $3(42.9)$ & $4(57.1)$ & 2.22 & 0.45 to 10.91 & 0.325 \\
\hline Antihypertensive & $16(84.2)$ & $3(15.8)$ & 0.44 & 0.13 to 1.52 & 0.196 \\
\hline Oxytocics & $34(63.0)$ & $20(37)$ & 0.60 & 0.34 to 1.07 & 0.085 \\
\hline Prostaglandins & $4(100)$ & $0(0)$ & 1.00 & & \\
\hline \multicolumn{6}{|l|}{ Mode of delivery } \\
\hline SVD & $431(76.8)$ & $130(23.2)$ & 1.00 & & \\
\hline AVD & $6(33.3)$ & $12(66.7)$ & 6.13 & 2.26 to 16.64 & 0.000 \\
\hline Emergency caesarean section & $96(68.1)$ & 45 (31.9) & 1.53 & 1.03 to 2.29 & 0.036 \\
\hline \multicolumn{6}{|l|}{ Meconium staining } \\
\hline Clear & $398(86.1)$ & 64 (13.9) & 1.00 & & \\
\hline MSL & $135(52.3)$ & $123(47.7)$ & 5.43 & 3.83 to 7.76 & 0.000 \\
\hline
\end{tabular}

AVD, Assisted Vaginal Delivery; LBW, Low Birth Weight; MSL, meconium-stained liquor; SVD, Spontaneous Vertex Delivery.

with mean lactate $(3.3 \pm 2.79 \mathrm{mmol} / \mathrm{L})$ in babies born through clear amniotic fluid. ${ }^{15}$ A second study compared neonates born through thick meconium-stained amniotic fluid and those born through thin meconium-stained amniotic fluid; the former group was found with higher gestational age, lower Apgar score and lower $\mathrm{pH}$ as well as higher umbilical cord blood lactate $>4.1 \mathrm{mmol} / \mathrm{L}$. This could predict occurrence of pulmonary haemorrhage and need for ventilation in the neonatal intensive care unit. ${ }^{16}$ From these findings, one can infer that in low-resource settings, meconium-stained amniotic fluid should be used as a sign of intrapartum fetal compromise 
Table 3 Multivariate analysis of factors associated with high umbilical artery lactate levels in neonates born in Mulago National Referral Hospital

\begin{tabular}{|c|c|c|c|c|c|}
\hline Characteristics & $\begin{array}{l}\text { Low lactate } \\
n=533(\%)\end{array}$ & $\begin{array}{l}\text { High lactate } \\
n=187(\%)\end{array}$ & aOR & $95 \% \mathrm{Cl}$ & $P$ value \\
\hline \multicolumn{6}{|l|}{ Baby's sex } \\
\hline Male & $258(69)$ & $116(31)$ & 1.71 & 1.16 to 2.54 & 0.007 \\
\hline \multicolumn{6}{|l|}{ Gravidity } \\
\hline Primigravida & $160(61.8)$ & 99 (38.2) & 2.78 & 1.89 to 4.08 & 0.000 \\
\hline \multicolumn{6}{|c|}{ Medication administered } \\
\hline None & $437(74.8)$ & $147(25.2)$ & 1.00 & & \\
\hline Antibiotics & $39(75)$ & $13(25)$ & 0.62 & 0.27 to 1.30 & 0.221 \\
\hline Anticonvulsants & $3(42.9)$ & $4(57.1)$ & 2.52 & 0.39 to 16.54 & 0.326 \\
\hline Prostaglandins & $4(100)$ & $0(0)$ & 1.00 & & \\
\hline \multicolumn{6}{|l|}{ Meconium staining } \\
\hline Clear & $398(86.1)$ & 64 (13.9) & 1.00 & & \\
\hline MSL & $135(52.3)$ & $123(47.7)$ & 5.85 & 4.08 to 8.47 & 0.000 \\
\hline
\end{tabular}

$P$ values in Bold are significant; less than 0.05

aOR, adjusted OR; MSL, meconium-stained liquor.

and a consideration for intervention. In our hospital, mothers in labour with meconium-stained amniotic fluid receive closer fetal heart rate monitoring while being counselled for possibility of emergency operative delivery. An alternative practice of intrapartum amnioinfusion is contentious and has not been adopted at our hospital; however, it could significantly improve neonatal outcome while reducing caesarean delivery rate and we recommend further studies in this subject in our setting. ${ }^{17} 18$ Our study affirms that babies born through meconiumstained amniotic fluid should be monitored closely in the immediate postpartum period considering admission to the nursery if they have breathing difficulty and/or fail to feed. A cord blood lactate level above $6.1 \mathrm{mmol} / \mathrm{L}$ would easily aid triage which of these babies need closer monitoring.

Babies born to mothers whose labour was augmented with oxytocin infusions were almost two times more likely to have high cord arterial lactate levels. This is a well-known risk in labour management due to the risk of uterine hyperstimulation and decreased placental perfusion resulting in fetal distress. It has also been found that mothers who received oxytocin for labour augmentation were found to have fetal intermediate/pathological cardiotocography tracings with significantly elevated umbilical cord lactate at birth. ${ }^{19}$ Lastly, a study of 80 term newborns delivered vaginally also found that fetal acidosis was significantly associated with oxytocin augmentation (OR 16.48, 95\% CI 1.21 to 22.6) during labour management. ${ }^{20}$ The decision to augment labour with oxytocin should be taken, well aware of the potential outcomes; communicating to the patient these risks and getting her consent for the intervention.

In our study, birth weight was not found to be significantly associated with differences in umbilical cord lactate concentration. A similar study found no significant difference in cord blood lactate concentration at various birth weight for term babies. ${ }^{21}$ The similarity between our two studies is that we included only term gestations.

To the contrary, studies have found that preterm and low birthweight babies $(<2000 \mathrm{~g})$ have been found with low cord blood $\mathrm{pH}$ and subsequent high lactate concentration at birth compared with term gestations of normal birth weight $(>2500 \mathrm{~g}) .^{22} 23$

The mode of delivery, too, was not found to be a risk factor for high umbilical cord blood lactate concentration after adjusted analysis in our study population. This contradicts a study in which neonates delivered by emergency caesarean section, especially for fetal distress, had significantly high lactate. ${ }^{24}$ The explanation for this difference could be because our study did not stratify its analysis based on the indication of the caesarean section. Secondly, even with assisted vaginal delivery, the number of babies born by this method ( 18 only) was not sufficient to deduce significant association with high umbilical artery lactate concentration.

As seen above, this study agrees with previous studies that certain maternal-fetal factors can be considered risk factors for fetal and neonatal acidosis. These can therefore be taken into consideration when making decisions 
during the peripartum period such as presence of a neonatologist to receive a baby or decision to deliver by emergency caesarean section. This study demonstrated the practicability of a portable point-of-care lactate metre in a busy obstetric unit; we recommend further research in our local setting studying feasibility of measurement of fetal scalp blood lactate using point-of-care devices. This could support decision-making when fetal compromise is suspected in presence of abnormal fetal heart rate patterns and meconium-stained amniotic fluid. This could avert potential adverse outcomes in the perinatal period while curbing the unnecessary rising caesarean section rate.

From the study, too, we observed that neonates with high cord blood lactate values had significantly higher frequency of adverse outcomes such as resuscitation, admission to the nursery, low Apgar score at $5 \mathrm{~min}$ and death compared with those with low blood lactate levels. In our setting and the rest of sub-Saharan Africa, umbilical cord lactate could have a role in triaging babies with higher likelihood of adverse outcomes and complications. We reiterate the opinion that this allows efficient allocation of resources such as manpower, limited nursery beds and other supportive interventions to babies with greater need. $^{25}$

A potential limitation of our study was that we drew one sample of fetal cord arterial blood as opposed to paired samples. This deviated from the standard practice of drawing two samples to validate if the sample is truly arterial and not venous.

We decided this due to resource constraint as analysing two samples per study participant would require more consumables and drastically raise the cost of the study. To mitigate the effect of this on our results, the study assistants were trained on repeated occasions to draw blood from the smaller calibre and thick-walled umbilical arteries. Secondly, establishing the true gestational age of our participants was difficult and we relied on recollection of menstrual dates since few mothers had a first trimester dating ultrasound scan on record. Lastly, our study did not explore the effect of maternal infections such as malaria and HIV on cord blood lactate levels and yet these are prevalent in our setting. A study in Malawi found neonates of mothers diagnosed with malaria although few, with significantly higher cord lactate levels and this deserves further investigation. ${ }^{25}$

\section{CONCLUSION}

We concluded that about a fifth of the babies born in Mulago National Referral Hospital during the study period had high umbilical artery lactate. The maternalfetal factors significantly associated with high umbilical artery lactate levels included: baby's sex, mother's gravidity, meconium-stained amniotic fluid and oxytocin administration during labour. Mother's age, birth weight, maternal blood pressure and mode of delivery were not significantly associated with high umbilical artery lactate levels. In one of the busiest labour suites in sub-Saharan Africa, clinical practice is guided mostly by foreign recommendations and data from foreign studies. The findings of this study conducted in the local setting are more likely to influence practice, and encourage implementation research in the applicability of newborn cord blood testing.

Acknowledgements Special thanks to the staff of the Department of Obstetrics and Gynecology-Mulago National Referral Hospital, my supervisors and the study team.

Contributors V0 was involved in concept development, data collection, analysis and research report writing. MMuy and MMus were involved in concept development and review of research report. JN was involved in concept development, data collection and review of research report. All the authors have agreed to be accountable for all the aspects of the work in this study.

Funding This research was supported by the Fogarty International Center of the National Institutes of Health, US Department of State's Office of the US Global AIDS Coordinator and Health Diplomacy and PEPFAR under award number 1R25TW011213.

\section{Competing interests None declared.}

Patient and public involvement Patients and/or the public were involved in the design, or conduct, or reporting, or dissemination plans of this research. Refer to the Methods section for further details.

Patient consent for publication Not required.

Ethics approval The research proposal was vetted by the Department of Obstetrics and Gynecology, Makerere University, and forwarded to the School of Medicine Research Ethics Committee (REC reference 2018-129). The study was also approved by the Mulago Hospital Research and Ethics Committee (reference MHREC 1537).

Provenance and peer review Not commissioned; externally peer reviewed.

Data availability statement Data are available in a public, open access repository. Extra data can be accessed via the Dryad data repository at http://datadryad.org/ with the doi: $10.5061 /$ dryad.crjdfn32f.

Open access This is an open access article distributed in accordance with the Creative Commons Attribution Non Commercial (CC BY-NC 4.0) license, which permits others to distribute, remix, adapt, build upon this work non-commercially, and license their derivative works on different terms, provided the original work is properly cited, appropriate credit is given, any changes made indicated, and the use is non-commercial. See: http://creativecommons.org/licenses/by-nc/4.0/.

\section{ORCID iD}

Victor Ogik http://orcid.org/0000-0002-7584-5097

\section{REFERENCES}

1 UN-IGME, Levels \& Trends in Child Mortality. United nations Interagency group for child mortality estimation. New York: UNICEF, 2018.

2 Low JA. Intrapartum fetal asphyxia: definition, diagnosis, and classification. Am J Obstet Gynecol 1997;176:957-9.

3 Bobrow CS, Soothill PW. Causes and consequences of fetal acidosis. Arch Dis Child Fetal Neonatal Ed 1999;80:F246-9.

4 White $\mathrm{CRH}$, Doherty DA, Newnham JP, et al. The impact of introducing universal umbilical cord blood gas analysis and lactate measurement at delivery. Aust N Z J Obstet Gynaecol 2014;54:71-8.

5 Low JA, Lindsay BG, Derrick EJ. Threshold of metabolic acidosis associated with newborn complications. Am J Obstet Gynecol 1997;177:1391-4.

6 Kaye D. Antenatal and intrapartum risk factors for birth asphyxia among emergency obstetric referrals in Mulago Hospital, Kampala, Uganda. East Afr Med J 2003;80:140-3.

7 Peduzzi P, Concato J, Kemper E, et al. A simulation study of the number of events per variable in logistic regression analysis. J Clin Epidemiol 1996;49:1373-9.

8 Modarressnejad V. Umbilical cord blood $\mathrm{pH}$ and risk factors for acidaemia in neonates in Kerman. East Mediterr Health $\mathrm{J}$ 2005;11:96-101. 
9 Westgate J, Garibaldi JM, Greene KR. Umbilical cord blood gas analysis at delivery: a time for quality data. Br J Obstet Gynaecol 1994;101:1054-63.

10 Fuyama Y, Shima Y, Shindo F, et al. Clinical significance of measuring lactate levels in cord blood to predict development of respiratory distress syndrom in neonates. JMAJ 2005;48:268-76.

11 Mohamed MA, Aly H. Impact of race on male predisposition to birth asphyxia. J Perinatol 2014;34:449-52.

12 Department of Economic and Social Affairs. United-Nations, sex differentials in childhood mortality, P. division, editor 2011.

13 O'Driscoll DN, Greene CM, Molloy EJ. Immune function? A missing link in the gender disparity in preterm neonatal outcomes. Expert Rev Clin Immunol 2017;13:1061-71.

14 Einikyte R, Snieckuviene V, Ramasauskaite D, et al. The comparison of umbilical cord arterial blood lactate and $\mathrm{pH}$ values for predicting short-term neonatal outcomes. Taiwan J Obstet Gynecol 2017;56:745-9.

15 Ojha RK, Singh SK, Batra S, et al. Lactate: creatinine ratio in babies with thin meconium staining of amniotic fluid. BMC Pediatr 2006;6:13

16 Mazouri A, Fallah R, Saboute M, et al. The prognostic value of the level of lactate in umbilical cord blood in predicting complications of neonates with meconium aspiration syndrome. J Matern Fetal Neonatal Med 2021;34:1013-9.
17 Pierce J, Gaudier FL, Sanchez-Ramos L. Intrapartum amnioinfusion for meconium-stained fluid: meta-analysis of prospective clinical trials. Obstet Gynecol 2000;95:1051-6.

18 Fraser WD, Hofmeyr J, Lede R, et al. Amnioinfusion for the prevention of the meconium aspiration syndrome. N Engl $J$ Med 2005;353:909-17.

19 Wiberg N, Källén K. Fetal scalp blood lactate during second stage of labor: determination of reference values and impact of obstetrical interventions. J Matern Fetal Neonatal Med 2017;30:612-7.

20 Su C-F, Tsai H-J, Huang C-C, et al. Fetal acidosis from obstetric interventions during the first vaginal delivery. Taiwan $\mathrm{J}$ Obstet Gynecol 2008;47:397-401.

21 Mongelli DM. Cord blood lactate and $\mathrm{pH}$ values at term and perinatal outcome: a retrospective cohort study 2010.

22 Wiberg N, Källén K, Herbst A, et al. Lactate concentration in umbilical cord blood is gestational age-dependent: a population-based study of 17867 newborns. BJOG 2008;115:704-9.

23 Hibbard JU, Hibbard MC, Whalen MP. Umbilical cord blood gases and mortality and morbidity in the very low birth weight infant. Obstet Gynecol 1991;78:768-73.

24 Kumar N, Yadav A. Role of umbilical cord arterial $\mathrm{pH}$ and lactate in newborn assessment of term antenatal women with hypertensive disorders of pregnancy. Clin Epidemiol Glob Health 2020;8:927-33.

25 Chilinda GK, Gadama LA, Stones W. Point-of-care umbilical arterial lactate and newborn outcomes in a low resource setting: cohort study. BMC Res Notes 2018;11:477. 